DOI 10.20396/temáticas.v27i54.12338

\title{
A CONSTRUÇÃO SOCIAL ACERCA DA BANALIDADE DO MAL EM HANNAH ARENDT
}

\author{
Vinicius Oliveira Seabra Guimarães ${ }^{1}$
}

\begin{abstract}
RESUMO: Esse artigo se propõe a analisar o conceito de 'banalidade do mal', como concebe a filósofa alemã de origem judaica, Hannah Arendt (1906-1975), especialmente a partir do julgamento de Adolf Eichmann, em 1961, em Jerusalém. Contudo, faz-se necessário registrar que a proposta aqui não é de caráter jurídico ou técnico acerca dos processos legais da condenação de Adolf Eichmann, pois isso requer outra abordagem teórica. Então, a proposta desse texto é compreender a noção filosófica e social da maldade como parte estrutural da sociedade moderna. Para tanto, na perspectiva arendtiana, entende-se que não há de um lado o mal e do outro lado o bem, de forma dicotomizada e dualística, pelo contrário, o percurso teórico-metodológico proposto por Hannah Arendt visa à compreensão do mal a partir dos bons, dos comuns, dos normais, sendo esses os agentes sociais quem mantém a lógica estrutural da 'banalidade do mal' no contexto da modernidade.
\end{abstract}

PALAVRAS-CHAVE: Hannah Arendt; Mal; Banalidade.

\section{THE SOCIAL CONSTRUCTION ON THE BANALITY OF EVIL IN HANNAH ARENDT}

\begin{abstract}
This article proposes to analyze the concept of 'banality of evil', as conceived by the German philosopher of Jewish origin, Hannah Arendt (1906-1975), especially since Adolf Eichmann's 1961 trial in Jerusalem. However, it is necessary to note
\end{abstract}

\footnotetext{
${ }^{1}$ Mestre e Doutorando em Educação pela Pontifícia Universidade Católica de Goiás (PUC Goiás) - linha de pesquisa: Educação, Sociedade e Cultura. Contato: vs.seabra@gmail.com
} 
that the proposal here is not of a legal or technical nature regarding the legal proceedings of the conviction of Adolf Eichmann, as this requires another theoretical approach. So the proposal of this text is to understand the philosophical and social notion of evil as a structural part of modern society. For this, in the Arendtian perspective, it is understood that there is not on one side the evil and on the other side the good, in a dichotomized and dualistic form, on the contrary, the theoretical-methodological path proposed by Hannah Arendt aims at the understanding of evil from the good, the common, the normal, and these are the social agents who maintain the structural logic of 'banality of evil' in the context of modernity.

KEYWORDS : Hannah Arendt; Evil; Banality.

\section{INTRODUÇÃO}

De início se faz necessário uma ressalva teórico-conceitual, indicando que o presente artigo não tratará acerca da bondade e seus desdobramentos coletivos e/ou filosóficos, pois tal categoria merece uma análise pormenorizada e específica, o que não é o objetivo aqui. Eis a razão de utilizar a categoria bondade com fonte em itálico. Nesse sentido, esse artigo se propõe analisar, especificamente, a lógica social e estrutural da banalidade do mal na perspectiva de Hannah Arendt, compreendendo que o horror e a perversidade se constituem a partir de estratégias de manutenção específica como será exposto ao longo do texto. O método utilizado na produção desse artigo é bibliográfico/documental e o problema que propomos responder é: a partir do julgamento de Adolf Eichmann, na perspectiva de Hannah Arendt, de que forma o mal se torna tão banal ao ponto de se estabelecer na estrutura social da sociedade moderna?

Segundo Hannah Arendt, o mal é trivial e não há em si profundidade alguma, daí a noção arendtiana de 'banalidade do mal'. Para ela, basta que haja pessoas supérfluas, banais e simplistas, pessoas essas que sigam, cotidianamente, a normalidade da vida - como um fotógrafo ou um burocrata - para que o mal consiga tão facilmente se estabelecer na sociedade. Entretanto, com isso, ela não minimiza as consequências individuais ou coletivas das horripilantes atrocidades que advém dessa incapacidade de julgar, criticar e conhecer a realidade. Pelo 
contrário, na concepção de Hannah Arendt, o mal em seu estágio máximo de perversidade, ou seja, em regimes totalitaristas, só se tornam tão aceitavelmente perversos por causa das ações dessas pessoas supérfluas, banais e simplistas - esses termos não são pejorativos ou depreciativos, apenas se referem à cotidianização da vida.

A banalização do mal está em conformidade com o processo de cotidianização da vida, sendo é nesse estágio em que a maldade se torna aceitável, praticável e corriqueira, mesmo que seus algozes nunca precisem engatilhar um revólver, ou empunhar uma faca, ou cometer qualquer ato considerável atroz. Basta-lhes seguir o cronograma, seguir as normas, seguir as regras e limitar sua capacidade de julgamento (conhecimento) a apenas suas próprias atividades individuais. A banalidade do mal, nesse sentido, é o estado de normose social em que não se questiona as ações coletivas e não se busca compreender a extensão dos atos individuais.

O mal, segundo Hannah Arendt, não é externo aos indivíduos, e, provavelmente, não se deixa conhecer-se a si mesmo por completo, talvez, esse seja o grande triunfo do mal, sua invisibilidade e naturalidade social (SILVA, 2013). Nesse viés, para o mal ter êxito, basta que a vida seja fracionada em intervalos existenciais descompassados com o coletivo; basta que o trabalho laboral seja dividido em etapas tantas que praticamente se torne incomunicável as partes do todo; e, basta que as fronteiras invisíveis do coletivo se tornem tão intransponíveis ao ponto de produzir um abismo entre o "eu" e o "outro". Contudo, aqueles que se permitem questionar, duvidar e conhecer, ou seja, ter profundidade, poderão romper com o ciclo da perpetuação da 'banalidade do mal', que, ao que tudo indica, já está em vigor na sociedade moderna.

\section{O JULGAMENTO DE ADOLF EICHMANN}

Hannah Arendt, a partir do julgamento de Adolf Eichmann, em 1961, propõe uma análise da banalização do mal na sociedade. Para ela, a maldade não se dá por causa da natureza de caráter ou de personalidade, mas sim pela incapacidade de julgar e conhecer as situações, os fatos, as estruturas e o contexto. Nesse sentido, o mal pode ser essencialmente 
praticado, perpetuado e até defendido por pessoas que vivem a naturalidade e a normalidade da vida comum, a exemplo de Adolf Eichmann, que era um medíocre burocrata a serviço do modelo político aceito e vigente na Alemanha nazista do final da Segunda Guerra Mundial (ARENDT, 1999).

A questão intrínseca ao julgamento de Adolf Eichmann era se ele poderia ser condenado pelas mortes nos campos de extermínios nazistas pelo simples fato dele ser um burocrata que fazia listas de partidas de trem entre outros trabalhos meramente burocráticos. Trabalho esse que era oficial, legítimo e ilibado perante a sociedade da época. Adolf Eichmann argumenta que não poderia ser condenado pelas mortes daqueles que ele nunca nem se quer viu a face, considerando que ele, propriamente dito, não estava praticando o mal, apenas obedecendo às ordens e executando suas responsabilidades, como afirma: "Nunca matei um judeu, nem um não-judeu - nunca matei nenhum ser humano. Nunca dei uma ordem para matar...” (ARENDT, 1999, p. 33). Contudo, é esse o ponto central da análise filosófica proposta por Hannah Arendt, pois para ela, o mal se ocupa da cotidianização da vida e da incapacidade crítica dos seus agentes sociais.

$\mathrm{Na}$ perspectiva de Hannah Arendt, a lógica de manutenção do mal tem que superar a superficialidade do visível e do corriqueiro, se faz necessário conhecer a essência estrutural, histórica, filosófica e social do próprio mal. Para tanto, não se pode ignorar as estruturas de manutenção da maldade que se faz instaurada no coletivo, não se pode contentar em eleger apenas um ou outro culpado, uma ou outra atitude boçal, satisfazendo desta forma, apenas os desejos de vingança, de passionalidade e de suposta justiça. Essa superficialidade acrítica de não questionar o cotidiano dificulta a compreensão acerca da dimensão e da profundidade do mal, e atrapalha a capacidade de apreender de que forma o mal se engendra na sociedade, pois se o mal é banal, como propõe Hannah Arendt, isso não quer dizer que a sua estrutura de manutenção o seja. Então, para se compreender o mal é preciso que haja capacidade de julgar, de conhecer e de avaliar a condição humana como sujeitos históricos-sociais (SILVA, 2013).

No caso de Adolf Eichmann, Hannah Arendt propõe que para não se banalizar o mal era necessário indagar para além do próprio Adolf 
Eichmann: “(...) ‘Por que os judeus?’ e ‘Por que os alemães?’, ‘Qual o papel das outras nações?’ e 'Até que ponto vai a responsabilidade dos aliados?” (ARENDT, 1999, p. 15). Ou seja, culpar e condenar um oficial burocrata do exército alemão em um julgamento com tons midiáticos e teatralísticos poderia apenas levantar uma cortina de fumaça frente às questões mais profunda acerca de como o mal se enraíza em uma determinada sociedade, como foi o caso da Alemanha nazista nas décadas de 1930 e 1940.

A percepção de que o mal, não necessariamente, tem estereótipo de perversidade e que não se resume aos extremos de brutalidade é fundamental para não se banalizar a lógica da maldade. Nesse sentido, Hannah Arendt (1999) propõe a contraposição: "uma coisa é desentocar criminosos e assassinos de seus esconderijos, outra é encontrá-los importantes e prósperos no âmbito público” (p. 28). A crítica aqui repousa sobre a percepção coletiva do mal que se estabelece em meio a um apelo público pela condenação de indivíduos e não pela compreensão crítica das estruturas, ideias e representações que dão ao mal a sua forma de horror. Nesse sentido, condenar nos anos de 1961 um burocrata de um sistema político ideológico exaustivamente estigmatizado pelo mal, já deposto desde 1945, não avança na compreensão da maldade, apenas satisfaz, superficialmente, um senso de suposta justiça coletiva daqueles que afirmam não suportar a maldade na sociedade, mas que tem dificuldade de vê-la no cotidiano, especialmente nas representações de sucesso, felicidade e liberdade.

Adolf Eichmann, durante o julgamento, tenta se valer da percepção coletiva de que o mal tem um estereótipo social e que, portanto, ele não representava esse estereótipo. Eichmann se ampara sob a argumentação de que ele estava apenas obedecendo a ordens de superiores e fazendo com destreza as atividades burocráticas a ele conferidas, sendo que ele jamais participou, viu ou esteve presente em qualquer ato de brutalidade, perversidade e de assassinato aos judeus (ou não-judeus). Nesse viés, na percepção de Eichmann, a maldade e ele nunca andaram de mãos dadas, por isso, não poderia ser culpado (ARENDT, 1999).

O argumento de Eichmann desvela duas vertentes de análise que vão desenhar a visão de Hannah Arendt acerca do mal: 1) Que na 
estrutura social de manutenção da maldade o mal passa por pessoas boas, competentes e responsáveis, e esses são os principais agentes de continuidade do próprio mal, exatamente por retirar do mal o estereótipo de mal; 2) Que o fato de um indivíduo não fazer in loco a maldade, não o torna inculpável por aquilo que, estruturalmente, ele ajuda a manter, inclusive e essencialmente, por aquilo que ele não ocupou-se de saber a partir dos impactos de suas próprias ações ou omissões.

No julgamento de Eichmann, conforme relato de Hannah Arendt, ele, por vezes, insistia na tese de que "não sou o monstro que fazem de mim. Sou uma vítima da falácia” (ARENDT, 1999, p. 269). A defesa insistiu nessa tese, alegando que obediência é uma virtude, não um distintivo de mau-caratismo. Para tanto, a defesa considerava que "sua culpa [de Eichmann] provinha de sua obediência, e a obediência é louvada como virtude. Sua virtude tinha sido abusada pelos líderes nazistas." (idem, ibidem). Em um olhar rápido e displicente, tal argumentação até pode parecer plausível, mas quando submetido a um critério mais meticuloso acerca da responsabilidade coletiva, da capacidade de raciocínio/ questionamento e da consciência coletiva, entre outros elementos filosóficos, tal argumentação não se sustenta, pois se as premissas podem até serem verdadeiras, a conclusão definitivamente não o é, configurando um silogismo falacioso.

$\mathrm{Na}$ percepção de Hannah Arendt (1999), Eichmann visivelmente (arquétipo), argumentativamente (oratória) e definitivamente (cotidiano) não era um "monstro", como ele mesmo se defendia no tribunal, mas "era difícil não desconfiar que fosse um palhaço" (p. 67), isso por causa da sua suposta infantil ingenuidade frente ao contexto de seu trabalho burocrático e sua função estrutural no contexto do nazismo da época. Então, nesse sentido, o mal para se estabelecer como prática aceitável bastava-lhe a omissão, a não curiosidade e a conveniência, o não conhecimento. Portanto, a obediência cega, crédula, desmedida e passional por parte de comuns agentes do governo pode ter sido um dos elos mais fortes de manutenção da maldade no período do nazismo, o que, provavelmente, não seria tão diferente nos dias atuais. Ou como a própria Hannah Arendt (2012) adverte: "A diferença fundamental entre as ditaduras modernas e 
as tiranias do passado está no uso do terror não como meio de extermínio e amedrontamento dos oponentes, mas como instrumento corriqueiro para governar as massas perfeitamente obedientes” (p. 25). Então, para que o mal se estabeleça como prática aceitável basta que as pessoas sejam supérfluas.

A partir do julgamento de Eichmann fica latente que a maldade não se dá apenas nos conluios do crime, mas especialmente nas fileiras dos cidadãos comuns. Logo, a maldade não provém do desejo de fazer o mal ou de uma natureza má propriamente dita, provém da falha no pensamento crítico e da incapacidade de julgar o cotidiano em que se está inserido. Por isso Souki (1998) considera que:

O homem Eichmann era o perfeito instrumento para levar a cabo a 'Solução Final': organizado, regular e eficiente tal qual a empreitada de que ele estava encarregado. $\mathrm{Na}$ sua função de encarregado de transporte, ele era normal e medíocre e, no entanto, perfeitamente adaptado ao trabalho que consistia em 'fazer as rodas deslizarem suavemente', no sentido literal e figurativo. Sua função era tornar a 'Solução Final' normal. [...] Eichmann representava o melhor exemplo de um assassino de massa que era, ao mesmo tempo, um perfeito homem de família (SOUKI, 1998, p. 92).

Nesse sentido, Hannah Arendt (1999) considera que ainda que a participação de Eichmann na "Solução Final" fosse acidental ou factual, produzindo uma suposta lógica de que "...onde todos, ou quase todos, são culpados, ninguém é culpado” (p. 301), ainda sim ele seria indesculpável, pois a todos é dado a condição de conhecer a abrangência de suas escolhas, responsabilidades e atividades. Logo, a banalização do mal, por meio da superficialidade dos seus agentes históricos, não priva seus atores de suas responsabilidades e culpabilidade frente à perversidade. 


\section{A DÚVIDA RADICAL E O RECONHECIMENTO DO MAL}

Extrapolando a análise de Hannah Arendt acerca do julgamento de Adolf Eichmann e para melhor comprovar e fundamentar os conceitos aqui expostos, será resgatada a história de Francisco Boix, que ficou conhecido como o "fotógrafo de Mauthausen". História essa que se tornou documentário em 2000 sob o título: "Francisco Boix, un fotógrafo en el infierno", dirigido por Llorenç Soler; também se tornou uma película cinematográfica em 2018 sob o título: "El fotógrafo de Mauthausen", dirigido por Mar Targarona. A história relata os acontecimentos entre os anos de 1938 a 1945, na cidade de Mauthausen, na Áustria, onde foi construído um dos maiores complexos de campos de extermínios nazista interconectados da Europa. Esse local foi utilizado durante sete anos como espaço de tortura e barbárie, sendo registrado por fotos pelos próprios agentes do exército nazista e alguns prisioneiros ajudantes no Departamento de Identificação do campo de extermínios, entre eles, Francisco Boix.

Após o fim da Segunda Guerra Mundial, em 1945, e com a divulgação das fotos reveladas a partir dos negativos escondidos por Boix, ele foi para Nuremberg, Alemanha, testemunhar no julgamento de Ernst Kaltenbrunner em que foi condenado e enforcado em 16 de Outubro de 1946. A partir dos registros de Bermejo (2015) é possível aproximar os fatos ocorridos em Mauthausen à discussão acerca da banalização e a cotidianização do mal, pois havia alguns agentes do exército nazista que não se sentiam culpados ou responsáveis pela perversidade que aconteceu nos campos de extermínios em Mauthausen, especialmente, no caso em destaque, os fotógrafos. O próprio Ernst Kaltenbrunner alegou não saber o que ocorria em Mauthausen, alegando, portanto, não poder ser culpado pelas atrocidades das quais ele não fez. Contudo, isso apenas reafirma as ponderações iniciais em que, baseado em Hannah Arendt, a maldade para se manter e permanecer só precisa dos cidadãos comuns fazendo ações comuns, ou seja, só precisa que haja uma banalização e uma cotidianização do mal para que a maldade seja praticada e aceita em um determinada sociedade. 
Um fotógrafo, um burocrata, ou qualquer outro trabalhador comum, pode vir a ser um receptáculo e uma incubadora do mal, para isso basta-lhes não questionar, basta-lhes a não curiosidade; basta-lhes o não conhecer. Na lógica descartiana o conhecimento é fruto primário da "dúvida sistemática"/ "dúvida radical", que inclui o questionamento exaustivo como base estrutural para o conhecimento. Nesse viés, é dado a todos os homens e mulheres, em todos os tempos históricos, a capacidade de questionar seus atos e os impactos de seus atos na estrutura social coletiva em que se inserem. Portanto, não questionar não torna alguém inculpável, pelo contrário, o torna essencialmente culpável, justamente por serem os seres humanos os únicos animais com capacidade de pensar, refletir, criticar e raciocinar. Logo, não questionar é, por si só, um convite para que a iniquidade, a atrocidade, a barbaridade, a crueldade, a improbidade, a maldade e a malignidade se estabeleçam estruturalmente em uma sociedade.

O mal quando visto como mal em sua forma pura, obviamente será rejeitado pela sociedade, pois os coletivos são adestrados a repelirem o mal quando esse é assim considerado pela maioria dos seus integrantes. Por isso, Hannah Arendt (2012) assevera que "o terror, contudo, assume a simples forma do governo só no último estágio do seu desenvolvimento" (p. 25). Por essa razão, o mal precisa da bondade, dos comuns, ou ao menos, da cotidianização do mal, para que valendo-se do arquétipo dos irrepreensíveis, a maldade seja gradativamente aceita como comum e normal. Então, o êxito do mal está em conseguir enxertar-se na estrutura comum, de gente comum, em trabalhos comuns, em vidas comuns, como no caso do fotógrafo (Mauthausen) e do burocrata (Eichmann). Pessoas essas que não questionaram suas ações para além de suas próprias ações, se contentaram em viver de forma particularizada, minimizada e fracionada.

A incapacidade de analisar a ação do trabalho individual como parte de um todo social, muito provavelmente, anteveem ao próprio Eichmann e também anteveem o próprio nazismo. Quiçá, essa desvinculação com o todo e essa inércia do conhecer acerca da integralidade da vida coletiva, tenham suas bases nas transformações sociais oriundas da Revolução Industrial (do final do século XVIII ao início do século XX), pois foi nesse 
período histórico que o mundo transmutou-se do modo de produção artesanal para o modo de produção em massa. Essa mudança não apenas mudou a forma de se trabalhar, mas mudou também a percepção histórica, social e coletiva dos indivíduos em relação à sociedade e suas responsabilidades coletivas.

Na produção artesanal, antes da Revolução Industrial, o trabalhador era responsável pela produção total do produto, desde a coleta dos insumos de matéria-prima até o uso final do produto por parte do comprador. Esse trabalho tinha como característica o envolvimento total do trabalhador naquilo em que ele produzia, no como ele produzia e no para quem ele produzia. O trabalho, nessa época, tinha uma conexão com a natureza, com a sociedade e com o consumo. Tudo era integrado, ainda que de forma precária, levando em consideração os fatores produtivos da referida época. Contudo, com advento do trabalho industrial, a partir da Revolução Industrial, o trabalho e o próprio trabalhador são fracionados e tem suas responsabilidades restritas a divisão do trabalho. Agora, não cabia ao trabalhador conhecer para além de suas atividades laborais específicas, isto é, não era responsabilidade saber o antes e nem o depois daquela fração de trabalho para o qual se foi contrato para executar. A esse processo de desvinculação do todo e de desconhecimento do todo, Marx (2008) chamou de alienação.

A Hannah Arendt não abordou essas conexões históricas da banalização do mal com a Revolução Industrial em seus escritos, não ao menos diretamente, talvez, parcialmente, em Origens do Totalitarismo (2012) e em $A$ condição bumana (2007), hajam algumas questões marginais a esse fato. Contudo, é possível fazer tais aproximações, pois no trabalho alienado não cabe o pensar, o criticar, o avaliar, o conhecer; apenas cabe o fazer e o executar a "minha" parte. É exatamente nesse espaço do fracionamento do trabalho humano e do próprio ser humano, que, talvez, o mal tenha concebido seu habitat predileto, pois são pessoas comuns fazendo trabalhos comuns, sem questionarem para além da divisão do trabalho que promovem a 'banalidade do mal'. A falta de uma visão omnilateral, holística e integral das ações/relações humanas favorece a noção de banalização e de cotidianização do mal, pois como temos argumentado a 
partir do julgamento de Eichmann, são os comuns, aqueles que são tidos como bons ou normais na sociedade, que formam a teia de trama e drama da maldade. Lembrando, nas palavras do próprio Eichmann: "minha honra é minha lealdade” (ARENDT, 1999, p. 121).

A banalização e cotidianização do mal, às vezes, pode provocar certo deslocamento da consciência para um local de exteriorização de si mesmo, onde a própria maldade não seja entendida como atitudes humanas conscientes, o que constitui-se em uma falácia, pois a capacidade cognitiva lhe permite questionar a todos, a tudo e, inclusive, a si mesmo. Por essa razão, Souki (1998), baseada em Hannah Arendt, afirma: "Para combater o mal não é possível enfrentá-lo como a um objeto, mas, como estamos envolvidos no processo de superá-lo, temos que procurá-lo dentro de nós mesmos" (p. 30). Nesse viés, não se pode conceber uma visão dualística do bem e do mal como que forças de natureza opostas e externas, como na ingênua ilustração de um anjinho em um ouvido a soprar boas ideias e no outro ouvido um diabinho soprando más intenções. Logo, os bons podem cometer atos maus, e os maus podem cometer atos bons, ou seja, ninguém é plenamente bom e ninguém é plenamente mau. Portanto, o que cabe aos seres humanos é, no mínimo, questionar, exaustivamente.

Hannah Arendt, explica o que ela chamou de 'banalidade do mal' da seguinte maneira:

Há alguns anos, em relato sobre o julgamento de Eichmann em Jerusalém, mencionei a 'banalidade do mal'. Não quis, com a expressão, referir-me a teoria ou doutrina de qualquer espécie, mas antes a algo bastante factual, o fenômeno dos atos maus, cometidos em proporções gigantescas - atos cuja raiz não iremos encontrar em uma especial maldade, patologia ou convicção ideológica do agente; sua personalidade destacava-se unicamente por uma extraordinária superficialidade (ARENDT, 1993, p. 145).

$\mathrm{Na}$ concepção de Hannah Arendt, o mal nunca é radical ou profundo, contrapondo a percepção de Kant. Para ela, o mal é sempre 
uma demonstração da superficialidade, da banalidade e, por assim dizer, da cotidianização da vida moderna, especialmente daqueles que perderam a capacidade de questionar a tudo e a todos, como propõe René Descartes. Por essa razão, o mal, na perspectiva de Hannah Arendt, é um problema filosófico, antes de ser um problema jurídico ou psíquico. Tanto o é, que ela ao escrever uma carta para o historiador e filósofo Gershom Scholem, afirma:

Minha opinião é de que o mal nunca é 'radical', é apenas extremo e não possui profundidade nem qualquer dimensão demoníaca. Ele pode cobrir e deteriorar o mundo inteiro precisamente porque se espalha como um fungo na superfície. Ele é 'desafiador-do-pensamento', como eu disse, porque o pensamento tenta alcançar alguma profundidade, chegar às raízes, e o momento em que se ocupa do mal é frustrado porque não há nada. Essa é sua 'banalidade'. Apenas o bem tem profundidade e pode ser radical (ARENDT apud SOUKI, 1998, p. 101).

A partir destas duas citações anteriores é possível constatar que, na percepção de Hannah Arendt, a 'banalidade do mal' é absolutamente corriqueira naquelas sociedades em que pessoas comuns são supérfluas, banais e simplistas - pois o mal apenas requer superficialidade. De contrapartida, o mal tem dificuldades de se estabelecer naquelas sociedades em que as pessoas comuns sejam críticas, questionadoras e conhecedoras - pois requer profundidade. Nesse sentido, a discussão é para além de um estereótipo do bem ou do mal. Hannah Arendt, provoca uma discussão filosófica acerca da condição humana na sociedade moderna que, de tempos em tempos, ao que parece, tende a flertar com a maldade, o ódio e a perversidade.

\section{CONSIDERAÇÕES FINAIS}

A contribuição de Hannah Arendt ao debate acerca do mal se dá na concepção de que a maldade não é externa aos indivíduos, nem é 
uma força mítica ou mística, muito menos uma pessoa com estereótipo ou natureza de perverso. O mal, assim como o bem, estão acessíveis aos seres humanos a partir de suas escolhas e mais propriamente dito, a partir de sua capacidade de questionar suas escolhas, levando em consideração o conhecimento sobre a amplitude daquilo que se faz e também pela dimensão daquilo que se omite de ser feito. Desconhecimento, portanto, não é justificável aos seres humanos, afinal, são os únicos animais que têm a capacidade de raciocínio, de lógica e de pensar, sendo-lhes imputada uma obrigação coletiva de usar desse distintivo como instrumento de aprofundamento filosófico e social, rompendo com a superficialidade, com a banalidade e com a cotidianidade da qual a sociedade moderna está, inertemente, submersa.

A 'banalidade do mal' está no fato de que pessoas comuns, fazendo atividades comuns, vivendo suas vidas comuns, podem estar impulsionando o movimento das engrenagens do horror na sociedade, ainda que estas não tenham conhecimento disso. Aliás, é intencional, que elas não tenham conhecimento do serviço que estão prestando a maldade, pois é assim que o mal consegue trafegar com certa liberdade entre as estruturas sociais, ou seja, por meio do desconhecimento. Por essa razão, Hannah Arendt contribuiu, substancialmente, para uma análise do mal a partir dos bons, dos comuns, dos normais - os mesmos que são os supérfluos, os banais e os simplistas - esses que podem ser fotógrafos ou burocratas, conforme analisado no texto.

Ao que tudo indica, a vida moderna favorece a proliferação do mal, pois não se há tempo de conhecer, não há disposição para questionar, não há intento de verificar, não há vontade para debater, não há interesse de ver além, não há curiosidade para enxergar o total, ou seja, há uma inquestionável superficialidade que rege a vida comum moderna. O trabalho alienado e o estímulo às virtudes honrosas do trabalho não favorecem a um aprofundamento da compreensão das estruturas, das ideias e das representações das quais participamos ativamente. Entretanto, a semelhança de Eichmann, ninguém é indesculpável e nem inculpável. Por isso, é válido reafirmar que somente aqueles que se permitem questionar, duvidar e conhecer, isto é, ter profundidade, poderão romper com o ciclo 
da 'banalidade do mal', que, inegavelmente, já está em vigor na sociedade moderna. Então, conclui-se que para o enfrentamento do mal se requer um profundo senso crítico acerca da realidade e das estruturas de manutenção da realidade para, então, perceber e compreender a extensão das ações individuais frente ao coletivo em que se está inserido.

\section{REFERÊNCIAS BIBLIOGRÁFICAS}

ARENDT, Hannah. A condição bumana. 10 ed. Rio de Janeiro: Forense Universitária, 2007.

ARENDT, Hannah. A dignidade da política: Ensaios e Conferências. Rio de Janeiro: Relume-Dumará, 1993.

ARENDT, Hannah. Eichmann em Jerusalém: Um relato sobre a banalidade do mal. São Paulo: Companhia das Letras, 1999.

ARENDT, Hannah. Origens do Totalitarismo. São Paulo: Companhia das Letras, 2012.

BERMEJO, Benito. El fotógrafo del horror: la historia de Francisco Boix y las fotos robadas a los SS de Mauthausen. Barcelona: RBA Libros, 2015.

MARX, Karl. Manuscritos econômico-filosóficos. São Paulo: Boitempo editorial, 2008.

SILVA, Thiago Dias da. Mal, modernidade e pensamento em Hannah Arendt. Sócrates e Eichmann em perspectiva. Dissertação (Mestrado) Universidade de São Paulo, Faculdade de Filosofia, Letras e Ciências Humanas, São Paulo, 2013.

SOUKI, Nádia. Hannah Arendt e a banalidade do mal. Belo Horizonte: UFMG, 1998.

Texto recebido em 29/04/2019 e aprovado em 18/11/2019 